Rev. Interd. em Cult. e Soc. (RICS), São Luís, v. 7, n. 2, p. 157- 178, jul./dez. 2021

ISSN eletrônico: $2447-6498$

\title{
Ingovernável da deficiência, sua radicalidade ontológica e seus devires clandestinos na educação e na filosofia
}

\section{The ungovernable of disability, its ontological radicality and its clandestine becomings in education and philosophy}

\author{
PEDRO ANGELO PAGNI \\ Professor adjunto da Universidade Estadual \\ Paulista Júlio de Mesquita Filho, UNESP \\ pedropagni@gmail.com
}

\section{RESUMO}

Este artigo analisa a dimensão ingovernável da deficiência, sua radicalidade ontológica e seus devires clandestinos na configuração neoliberal da biopolítica. Partimos para tanto do ensaio Os instintos e as instituições de Gilles Deleuze e do curso Os anormais de Michel Foucault, com vistas a discutir a proveniência da ingovernabilidade da deficiência e suas formas de governo pelas instituições educacionais. Retratamos o modo como o retardo de Charles Jouy revela um hiato entre a sua organização biológica, a mecânica instintual e a economia do prazer, encontrando aí sua ingovernabilidade não somente a ser governada, como também a servir de indagação às práticas inclusivas atuais, seus devires clandestinos e sua biopotência para resistir à governamentalidade neoliberal.

Palavras-chave: Ingovernável. Deficiência. Corpo. Filosofias Da Diferença.

\begin{abstract}
This article analyzes the ungovernable dimension of disability, its ontological radicality and its clandestine becomings in the neoliberal configuration of biopolitics. For this, we start from the essay The instincts and institutions by Gilles Deleuze and from the course The abnormals by Michel Foucault, with a view to discussing the origin of the ungovernability of disability and its forms of government by educational institutions. We portray how Charles Jouy's retardation reveals a gap between his biological organization, instinctual mechanics and the economy of pleasure, finding his ungovernability not only to be governed, but also to serve as an inquiry into current inclusive practices, their becomings clandestines and their biopotency to resist neoliberal governmentality.
\end{abstract}

Keywords: Ungovernable. Deficiency. Body. Philosophies Of Difference.

Ingovernável da deficiência, sua radicalidade ontológica e seus devires clandestinos na educação e na filosofia

Toute institution impose à notre corps, même dans ses structures involontaires, une série de modèles, et donne à notre intelligence un savoir, une possibilité de prévision comme de projet. Nous retrouvons la conclusion suivante: L'homme n'a pas d'instincts, il fait des institutions. L'homme est un animal en train de dépouiller l'espèce. Aussi, l'instinct traduirait-il les urgences de l'animal, et l'institution, les exigences de l'homme : l'urgence de la faim devient chez l'homme revendication d'avoir du pain. Finalement, le problème de l'instinct et de l'institution sera saisi, à 
Rev. Interd. em Cult. e Soc. (RICS), São Luís, v. 7, n. 2, p. 157- 178, jul./dez. 2021

ISSN eletrônico: 2447-6498

son point le plus aigu, non pas dans les « sociétés » animales, mais dans les rapports de l'animal et de l'homme, quand les exigences de l'homme portent sur l'animal en intégrant celui-ci dans des institutions (totémisme et domestication), quand les urgences de l'animal rencontrent l'homme, soit pour le fuir ou l'attaquer, soit pour en attendre nourriture et protection. (DELEUZE, 1955, p. $\mathrm{XI})^{1}$

Esta conclusão da apresentação de Gilles Deleuze à coleção Texts $e$ documents philosophics, organizada por Georges Canguilhem, em 1955, parece aglutinar os problemas em torno dos quais uma série de estudos foram desenvolvidos nos anos de 1960 e 1970, sendo signos de uma época que ainda não se findou. Gilles Deleuze com Félix Guarrari (2004) retomaram a temática em $O$ Anti-Édipo, publicado em 1973. Filósofos como Jean-François Lyotard (1981; 1990) viram nesse debate a possibilidade da elaboração de uma economia política libidinal, problematizando os dispositivos que a empreendem, enquanto que outros, como Michel Foucault (1988), mesmo sem propor algo dessa natureza, teve em torno da questão da erótica e dos dispositivos de sexualidade o centro orbital de sua obra- se o considerarmos no giro que deu em seu projeto a partir da publicação dos volumes da História da Sexualidade, algo que vinha ensaiando desde seus cursos sobre o tema, publicados postumamente. Considerando esse contexto filosófico francês, em que maio de 1968 teve um papel histórico decisivo, essa apresentação de Deleuze soa como um prenúncio e a conclusão a que chega sobre o modo como o instinto é maquinado pela instituição ressoa como o emblema de uma geração de intelectuais sobre os quais Georges Canguilhem teve grande influência, juntamente com Georges Bataille e Maurice Blanchot. É como se essa geração tivesse legado àquela uma herança, revitalizada a partir dos acontecimentos históricos de 1968 e da inquietude dessa geração de intelectuais franceses que firmaram em seu horizonte o problema político de que qualquer alternativa para os impasses do capitalismo, no período, passaria necessariamente pelo ensaio de novos processos de subjetivação que escapassem às suas amarras e capturas. Assumem para tanto reacender o debate sobre a vicissitude instintual, as suas tendências em alcançar o prazer ou a satisfação do desejo como meio de liberação das fixidez da subjetividade construída pelos jogos de poder instituídos por esse modo de produção e a possibilidade de romperem as minas postas pelos agenciamentos institucionais,

\footnotetext{
${ }^{1} \mathrm{Na}$ TB: "Não há tendências sociais, mas somente meios sociais de satisfazer as tendências, meios que são originais porque são sociais. Toda instituição impõe a nosso corpo, mesmo em suas estruturas involuntárias, uma série de modelos e, dá à nossa inteligência um saber, uma possibilidade de previsão, assim como de projeto. Nós reencontramos a conclusão seguinte: o homem não tem instinto, ele faz instituições. O homem é um animal se despojando da espécie. Assim, o instinto traduziria as urgências animais e a instituição as urgências do homem: a urgência da fome torna-se no homem a reivindicação de ter pão. Finalmente o problema do instinto e das instituições será aprendido, em seu ponto mais agudo, não nas "sociedades" animais, mas nas relações do animal e do homem, quando as exigências do homem incidem sobre o animal integrando-o em instituições (totemismo e domesticação), quando as urgências do animal encontram o homem, seja para dele fugir ou atacá-lo, seja para dele esperar alimento ou proteção.” (DELEUZE, 2005, 137, grifos no original)
} 
Rev. Interd. em Cult. e Soc. (RICS), São Luís, v. 7, n. 2, p. 157- 178, jul./dez. 2021

ISSN eletrônico: $2447-6498$

como móveis de uma intensa luta para a consecução daquelas tendências, a reforma e a transformação dessas mesmas instituições.

A questão que se discute neste artigo é a de saber em que medida essa equação entre as instituições e os instintos foi se tornando uma zona indiscernível, ao ponto de o homem não fazer instituição, mas ser usado por ela para manipular as suas tendências e colocar os instintos no centro dos jogos de poder instituídos, sobretudo, em sua possível gestão. A instituição faz isso ao deixar de regular a existência singular daqueles que a habitam como norma para imperar sobre ela como uma lei, particularizando-a e individualizando-a como uma totalidade a ser encarnada e produzir o autocontrole necessário para afastar os excessos instintuais e reduzir a emergência de tendências contrastantes às medianas. Por seu turno, os instintos não satisfeitos por essa regulação institucional, nem pelo autocontrole imposto ao corpo singular, parecem ser mobilizados por tendências comuns, algumas vezes, para destrutir a tudo que represente algum estranhamento a esse eu totalizado, alimentando o ódio contra o outro e ao que afete essa individualização, (re)produzindo a sua estratificação, a fixação de seus fluxos e a limitação de sua economia libidinal. Raramente, esses instintos se reúnem para criar ou para forçar a criação de espaços outros na instituição, dando lugar ao estranho, ao diferenciado e ao que excede a regulação de seus fluxos, potencializando, antes do que as existências singulares, processos de subjetivação que reorganizam suas forças em torno de tendências comuns. Aliás, esses tendentes desvios comuns e os excessos instituais de existências singulares são vistos pela instituição e por toda a maquinaria coletiva que a compreende como uma ameaça a ser evitada e como um acontecimento cujo planejamento poderia prevenir, dirigindo a sua força desreguladora para um fim permitido e para práticas que neutralizassem seus efeitos de poder, mantendo intacta a hierarquia e a dominação existentes.

Nesse registro, a força destrutiva dos instintos gera uma zona de risco para o corpo que singularmente desvia de seu enquadramento institucional e de um padrão social. Uma zona em que, o que se supõe útil socialmente e governável, emerge como uma força ingovernável, desencadeada por uma potência inconsciente ainda não capturada ou, quem sabe, incapturável. É essa força que irrompe numa série fragmentada de acontecimentos históricos e que denotam uma crise de governamentalidade que nos interessa discutir aqui, juntamente com essa potência de diferenciação que repercute nos corpos ditos desviantes. Afinal, a hipótese deste artigo é a de que aí parece ser possível encontrar um indício afetivo e um terreno estético de emergência dessa forca, onde a inteligibilidade das ações individuais destoa das reações específicas produzidas pelas tendências comuns lançadas sobre esse 
Rev. Interd. em Cult. e Soc. (RICS), São Luís, v. 7, n. 2, p. 157- 178, jul./dez. 2021

ISSN eletrônico: 2447-6498

organismo e onde a consciência de seu sentido social é substituída pela comunhão múltipla e caótica resultante dos encontros dos corpos que habitam a instituição.

Uma vez circunscrito o terreno e os pontos de irrupção onde emergem parece ser possível nos encontrarmos com a inumanidade da educação, quando focamos esse campo. Afinal, como sugere Lyotard (1997, p.12), "toda educação é inumana", se considerarmos as contradições, jogos de poder e terror, mesmo a referente à " "boa maneira" de educar as crianças", o que, por um lado, gera certa melancolia, e, por outro, faz emergir uma "força inumana desreguladora". É desse ponto de vista que, especificamente, gostaríamos de falar sobre esse ingovernável da deficiência, destacando a sua radicalidade ontológica e os devires clandestinos que nutrem essa força inumana desreguladora e compõe suas formas de subjetivação. Para isso, vamos estabelecer uma interlocução com a obra de Michel Foucault e alguns de seus intérpretes e críticos para situar melhor esse problema, sobretudo, frente aos dispositivos de inclusão institucionalizados, em particular, nas escolas, utilizando-os como exemplo daquela captura do prazer em concorrência com outras formas de comunhão e de potência dessas formas de existência ditas deficientes.

\section{Ingovernável}

No livro Sociedade ingovernável, Grégoire Chamayou (2020, p. 22) argumenta que, diferentemente da governamentalidade que designa "uma disposição interna ao objeto de ser conduzido, sua propensão a deixar-se dirigir, a docilidade ou a ductilidade dos governados", a ingovernabilidade se caracteriza como "uma contra disposição indomável, um espírito de insubordinação, uma recusa de ser governado" de determinada forma.

Nada de novo se levarmos em conta as considerações de Michel Foucault (1997) sobre a crítica e a governamentalização. A novidade assinalada por esse autor, contudo, é o fato de compreender essa ingovernabilidade como "uma situação hipotética", "uma conjuntura" que poderia resultar "[...] de uma disfunção ou da falência do aparelho governamental, mesmo que os governos se mostrem dóceis" (CHAMAYOU, 2020, p. 22-23). Isso significa identificá-la como um "fenômeno de paralisia institucional", que pode resultar, por exemplo, de inúmeras causas, dentre elas de um movimento de desobediência civil. De acordo com Chamayou (2020, p. 23):

De modo esquemático, a crise de governabilidade pode ter duas grandes polaridades: a de baixo, dos governados, e a de cima, dos governantes; e duas grandes 
Rev. Interd. em Cult. e Soc. (RICS), São Luís, v. 7, n. 2, p. 157- 178, jul./dez. 2021

ISSN eletrônico: 2447-6498

modalidades: a revolta ou a paralisação, governados rebeldes ou governantes impotentes - e ambos os aspectos podem evidentemente se combinar. Lênin teorizava que apenas quando “os 'de baixo' não querem e os 'de cima' não podem continuar vivendo da forma antiga" a "crise governamental" é capaz de se transformar em crise revolucionária.

A aspiração desse autor parece ser a do despertar dessa crise revolucionária. Para Foucault, segundo Chamayou (2020, p. 23-24), a crise da governamentalidade não se trataria somente numa "revolta das condutas", como também de um 'bloqueio do "dispositivo geral de governamentalidade", ocasionada por razões endógenas, irredutíveis às crises econômicas do capitalismo, ainda que a elas articulado. De acordo com ele, Foucault teria vislumbrado que o que estaria 'prestes a ser bloqueado era a "arte liberal de governar", que não deve ser entendida (seria um anacronismo) como o neoliberalismo no poder, mas como aquilo que, no "liberalismo embutido", chamam de uma forma de compromisso instável como resultado da associação entre economia de mercado e intervencionismo Keynesiano.' (CHAMAYOU, 2020, p. 24) A diferença seria a de que, ao fazer isso, o filósofo francês teria perspectivado, com o bloqueio do dispositivo da "arte liberal de governo", rearranjos significativos. Desse ponto de vista, a sociedade seria ingovernável não em si, mas na forma como a queremos governar atualmente, o que implicaria em concluir que não haveria ingovernabilidade absoluta, somente relativa, sendo nessa diferença que reside o objeto e o desafio constitutivo de toda arte de governar.

Não é à toa que situa esse autor a explosão dessa ingovernabilidade a partir de maio de 1968 com os movimentos que de lá para cá produziram lutas identitárias ascendentes, assim como lutas transversais (com alianças ou não), se apresentando como movimentos múltiplos da sociedade civil, decorrente de embates locais e suscitadores de devires minoritários, contra o qual, por sua vez, se produziram formas globais de governamentalidades reativas, com vistas a contê-los, integrá-los ou incluí-los como parte da repartição do governo biopolítico da população.

Não obstante essa esquematização geral acerca do que se pode chamar de crise de governamentalidade das instituições em grande medida porque os instintos múltiplos e os agenciamentos das forças inumanas desreguladoras se insurgem inadvertidamente contra os dispositivos nela instaurados, é possível no projeto filosófico de cada um desses filósofos encontrarmos elementos para pensar a ingovernamentalidade desses corpos no âmbito não somente do corpo-espécie ou da biopolítica da população, como também no individual ou no de sua anátomo-político. Se esse foco na biopolítica da população nos permitiria compreender 
Rev. Interd. em Cult. e Soc. (RICS), São Luís, v. 7, n. 2, p. 157- 178, jul./dez. 2021

ISSN eletrônico: 2447-6498

a envergadura das formas de governamentalidade descendente, dos agenciamentos coletivos e, consequentemente, dos efeitos de poder sobre os processos de subjetivação, provavelmente, esse vislumbre dos desvios nos ajudaria a pensar nas resistências desses corpos a dispositivos disciplinares, de normalização, de segurança e de inclusão que cimentam, alinham um ao outro e articulam essa micropolítica com aquela macropolítica. Muitas vezes, esse alinhamento e articulação dos dispositivos produzem, para além do agenciamento de poder e de governamentalidade necessário ao maquinismo social, formas de dominação e promovendo tendências de vida fascistas, ocorrentes na existência ordinária e no mundo comum, que impregnam nossas práticas, gestos e hábitos tornando-os operantes, naturalizados e, por vezes, obscuros, por mais normalizados que possam parecer.

Dentre os projetos filosóficos mencionados, o foucaultiano auxilia-nos a tornar mais preciso nesse embate com os dispositivos presentes nas instituições uma face de normalização na qual repercute certo exercício de poder por individualização nos processos de subjetivação se sobrepondo a espécie e produzindo sínteses ou modelos sociais em que os instintos são secundarizados em relação à sua inteligibilidade e a tão propagada consciência. Nesse movimento encontramos também algumas pistas de certa ingovernamentalidade do anormal ou de um estado que se denomina de deficiência, assim como a sua estigmatização como um déficit ontológico, por fazer circular em e para fora de si devires minoritários, denotando socialmente uma valoração negativa, como um "ser menos", para usar uma expressão de Pelbart (2019).

\section{Da deficiência como um estado à sua ingovernabilidade}

Caso sigamos essas pistas na obra de Foucault, encontramos um quadro bastante interessante para situar historicamente, no âmbito arqueológico dos saberes psiquiátricos, o que se concebe como anormalidade. Ao nosso juízo, o ponto de maior relevo é, com o desenvolvimento da psiquiatria do século XIX, o registro arqueológico de a anormalidade deixar de ser atribuída exclusivamente a uma condição patológica do organismo e passar a ser considerada um estado em que a patologia se torna dispensável para que a condição de anormal se generalize.

Precisamente, segundo Foucault, esse estado é um "discriminante radical", pois, quem está sujeito a um estado "não é um indivíduo normal”, caracterizando-o como "anormal" na 
Rev. Interd. em Cult. e Soc. (RICS), São Luís, v. 7, n. 2, p. 157- 178, jul./dez. 2021

ISSN eletrônico: 2447-6498

medida em que pode haver doenças físicas e psicológicas conectados a seu estado, juntamente com as deformações, distúrbio funcionais, impulsos ou atos que sejam considerados psiquiátrica ou juridicamente desviantes. E, conclui ele:

\begin{abstract}
Em suma, tudo o que pode ser patológico ou desviante, no comportamento ou no corpo, pode ser efetivamente produzido a partir do estado. É que o estado não consiste em traços mais ou menos acentuados. O estado consiste essencialmente numa espécie de déficit geral das instâncias de coordenação do indivíduo. Distúrbio geral no jogo das excitações e das inibições; liberação descontínua e imprevisível do que deveria ser inibido, integrado e controlado; ausência de unidade dinâmica - é isso tudo que caracteriza o estado. (FOUCAULT, 2010, p. 273, grifos meus)
\end{abstract}

Com essa generalização da anormalidade a psiquiatria acolheria em seu campo de saber qualquer conduta "[...] a partir do momento em que ela é fisiológica, psicológica, sociológica, moral e até juridicamente desviante" (FOUCAULT, 2010, p. 274), descobrindo um conjunto estrutural que funciona conforme seu desenvolvimento, isto é, conforme a sua interrupção ou a sua regressão a um estágio anterior. É a luz dessa perspectiva que o desvio se qualifica e a deficiência se apresenta como uma condição de determinados indivíduos, que a carregam em seu campo de inscrição corpórea, não tendo como escapar desse registro, desse estado geral e, consequentemente, desse estigma.

Juntamente com a deficiência nasce o estigma social de quem a encarna como signo, como uma etiqueta que uma vez colada à pele, nada a faz sair e que serve para diferenciar esse indivíduo dos demais: não por suas qualidades, potencialidades, mas por seus limites, disfunções e déficits. Aquele que é visto como anormal, por esse estigma, passa a ser tratado a partir dessa sua condição e como o estado que a define, representando sempre o perigo da anomia social do corpo-espécie. E, por sua vez, o que é visto como perigo é cercado, estrategicamente, por uma série de cuidados de gestão por parte do governo biopolítico da população, ao mesmo tempo em que por dispositivos capazes de neutralizarem sua ocorrência. É assim que se tenta evitar acontecimentos que coloquem em risco o governo dos vivos, que gerem o caos, a escassez e a morte.

O perigo mencionado, porém, é representado pelo anormal estigmatizado, pelos estigmas dos desvios que indicam anomia social. Ele provoca com isso a estigmatização de toda diferença que se encarna nos corpos singulares, grupos ou comunidades cujos encontros com os demais corpos podem curto-circuitar as relações, por vezes frágeis, do tecido social. Quanto mais inapreensível, incontrolável e ingovernável são vistos tanto esses encontros quanto aquelas singularidades, a ameaça representada parece ser maior. Talvez, isso ocorra em razão de que também maior fosse a potência de esses corpos e seus encontros 
Rev. Interd. em Cult. e Soc. (RICS), São Luís, v. 7, n. 2, p. 157- 178, jul./dez. 2021

ISSN eletrônico: 2447-6498

extrapolarem os limites do biopoder e ampliarem a fratura da biopolítica, dado a percepção dos efeitos de suas forças desreguladoras.

Essas forças cujos feixes atravessam, circulam e, por vezes, são produzidas na sua relação com determinados corpos foram aquelas que a psiquiatria tentou decodificar, durante o século XIX. Por meio de seus saberes e tecnologias a psiquiatria procurou exercer sobre as três figuras do medo - o monstro, o incorrigível e o pequeno onanista -, segundo Foucault (2010), um poder capaz de livrar os demais daqueles corpos que o encarnavam. Em torno dessas três figuras que se complementam e se intercambiam entre si, por sua vez, teria nascido um conjunto de saberes e de poderes que se dedicaram a correção das anomalias, incidindo sobre os desvios e deformações dos corpos nas quais se inscrevem por esse olhar alheio e ajuizador.

É assim que o monstro, figura que alinha a animalidade ao reino humano, que mescla as espécies e os dois sexos (ou gêneros), que mistura vida e morte e as formas de sobrevida daqueles que nascem com deformações físicas, se apresenta como uma transgressão dos limites naturais, das classificações, dos enquadramentos sociais e das leis jurídicas. De modo análogo é atribuído ao incorrigível esse alerta de perigo, após inúmeras tentativas de reeducação e de correção é atribuído esse perigo. Se busca também na incorrigibilidade, uma justificativa funcional, como se a essa acepção de ciência na qual se sustenta a psiquiatria e a medicina social pudesse conhecer a disfunção orgânica que caracteriza essa outra excepcionalidade mais frequente: a daquele ou daquela que não se dobra aos dispositivos disciplinares, cujo corpo não se dociliza em razão da natureza instintiva que extrapola o registro biológico.

A psiquiatria de meados do século XX não poupou esforços para compreender a mecânica desse instinto e as formas como agenciá-los, ainda num plano psicofisiológico e anatômico, para corrigir seus fluxos mediante o isolamento, a internação asilar, acompanhados de tratamentos traumáticos como os de choque e, posteriormente, farmacológicos. Por sua vez, no campo jurídico a criminalização da incorrigibilidade ocorre entre a reclusão social pelo sistema prisional e pelos hospitais psiquiátricos, uma vez que os crimes cuja imputação identifique sua prática em função de qualquer desrazão, debilidade intelectual ou, mesmo, vulnerabilidade que demarquem sua vida pregressa, considerados como atenuantes. Foi no âmbito desse registro social que artes de governo liberais como a pedagógica e instituições como a escola, no século XIX, foram mobilizadas para corrigir o desvio inscritos no corpo, especialmente, no corpo infantil, colocando-o no caminho da normalidade, evitando sua dispersão na anomalia e, sobretudo, na anomia. 
Rev. Interd. em Cult. e Soc. (RICS), São Luís, v. 7, n. 2, p. 157- 178, jul./dez. 2021

ISSN eletrônico: 2447-6498

A descoberta da infância, juntamente com a da sexualidade produziram o terceiro foco de atenção ao perigo: a eventualidade do distúrbio sexual atribuído a estados de anormalidade cujo sinal seria dado com o pequeno onanista e cujo combate deveria começar na infância. Por sua vez, o destaque à sexualidade é importante nesta ocasião, pois passa a se tornar de algo velado a propagado, dentro de certa codificação supostamente médico-científica. Se, antes, a sexualidade era um campo em torno do qual se silenciava, a partir de então ele se vê abarcado por toda uma tecnologia positiva de poder. Ao invés de calá-la, tal tecnologia força a sexualidade a revelar-se como um âmbito de disputa do poder por saberes e técnicas como a psiquiatria, a psicanálise e a sexologia, por um lado, e a extrapolar-se num prazer que desborda os limites da pele, como uma potência outra, inapreensível, que não se converte em ato, tampouco se esgota no desejo, difundindo-se sem ser plenamente apreendida, por outro.

Nesse contexto de circulação do prazer e de sua apreensão por saberes especializados, Foucault (2010) chama atenção para a sexualidade infantil, circunscrevendo suas análises à prática da masturbação, considerada no século XIX como um sintoma de anormalidade e, de um modo mais amplo, como uma economia do prazer, com seus fluxos e contenções ${ }^{2}$. Essa economia de acordo com ele começa a ser decodificada pelos saberes mencionados, a ser usada nas artes de gestão do corpo produzidas no período e a ser sacramentada, desde então, como uma espécie de autogoverno da vida.

\footnotetext{
${ }^{2}$ A restrição das intensidades do prazer e das potencialidades do desejo aos saberes desse campo psiquiátrico só se tornou possível frente a certa contenção e, até mesmo, violência contra os extravasamentos que produzem no corpo, alimentados por ritos e dispositivos pastorais de exame que remontam a sua concepção como carne. Nessa carne a lei repercute ostensivamente e a culpa é sentida pelo ato de transgressão de certa experiência (interior) que conecta o humano aos animais e ao cosmos, por assim dizer, sendo expiada pela sua confissão. Na carne objeto desses saberes a ciência atua configurando essa cura pela fala ou pela confissão em técnica reveladora de si, expiadora da culpa e, também, reparadora dessa falta produzida pela interdição do prazer. A diferenciação feita por Foucault é a seguinte: "O antigo exame era, no fundo, o inventário das relações permitidas e proibidas. O novo exame vai ser um percurso meticuloso do corpo, uma espécie de anatomia da volúpia. É o corpo com suas diferentes partes, o corpo com suas diferentes sensações, e não mais, ou em todo caso muito menos, as leis da união legítima, que vai constituir o princípio da articulação dos pecados de luxúria. O corpo e seus prazeres é que se tornam, de certo modo, o código do carnal, muito mais que a forma requerida para a união legítima" (FOUCAULT, 2010, p. 160). É a expiação da carne que se torna o objeto de codificação desses saberes relacionados à sexualidade e de suas tecnologias específicas de poder, dentre elas o exame. Inclusive, essa codificação da carne procura ultrapassar certa "cartografia pecaminosa do corpo", isto é, as proibições relacionadas aos toques, à masturbação, as palavras sujas e a oitiva excitante ou pornográfica, elegendo-as como um campo de inscrição da proibição corpórea a ser confessada, para se centrar na problemática do prazer e do desejo. Não seria mais, portanto, segundo ele, o problema escolástico da distinção entre os atos e os pensamentos proibidos, sendo tanto o primeiro quanto o segundo condenados em razão de seu potencial perigo para uma existência pura, mas uma "espécie de fisiologia moral da carne", onde a infração da lei deixa de corresponder parcialmente ao "modelo jurídico da penitência", passando a ser conduzida por uma "dialética do deleite" que circunscreve o prazer e o desejo ao próprio corpo. Sobre esse corpo de prazer e de desejo operaria o exame, investindo sobre suas faltas e falhas, encarnando as infrações para curá-las nessa operação em que se faz discurso.
} 
Rev. Interd. em Cult. e Soc. (RICS), São Luís, v. 7, n. 2, p. 157- 178, jul./dez. 2021

ISSN eletrônico: 2447-6498

Embora Foucault (2010) utilize suas análises para evidenciar as consequências dessa economia para a elevação do estatuto da anormalidade a um estado e para a sua estigmatização enquanto corpo que encarna a deficiência, essa dimensão permanece numa inscrição de aspectos obscuros em sua obra. Ou, como preferimos expressar aqui, como uma alusão ao ingovernável do governo dessas existências em que se inscrevem, desde então, no cenário médico, psicológico e pedagógico. Para vislumbrar esse ingovernável bastaria observarmos o modo como a carne foi cartografada e codificada em instituições como as escolas modernas, seguindo as próprias indicações de Foucault (2010), para chegarmos às conclusões que se seguem.

Tudo que no corpo escape a (sobre)codificação, que exceda energeticamente o desejo elaborado, repercutindo a intensidade prazer na relação consigo ou com outrem e evidenciando uma assinatura de inscrição é tratado como desvio e como anomalia. Convulsões, contraturas, espasmos, deformidades nos fluxos que escapam esse código e seus aparatos instintuais são sintomas de anormalidade e, enquanto tais, marcas a serem tratados pela psiquiatria, a sexologia e a psicanálise, por meio de tecnologias e elaborações do eu que aplainam a subjetividade. Afinal, esses saberes e suas tecnologias colaboram para dar a tais sintomas e sua causa um registro de inteligibilidade que visa evitar qualquer coisa que remeta ao antigo "distúrbio carnal" e, modernamente, demarcar como desvio às resistências do corpo a essas formas de disciplinamento, isto é, contrapoderes produzidos pela intensificação do prazer, que transbordam (refletidamente ou não) certa economia libidinal.

No âmbito dessa economia é que se passou a julgar os sintomas dos desvios sexuais adultos, patologizando-os ou, mesmo, criminalizando-os. Reconhece-se também que a sua correção deveria começar pelo alcance de suas causas infantis e, na realidade, evitando a sua eclosão na própria infância, em instituições como a família e a escola. Ao herdarem o “domínio da carne" do poder pastoral, essa ação coordenada de saberes médicos e instituições sociais começam "um controle higiênico e com pretensões científicas da sexualidade", exercendo sobre ela um domínio psiquiátrico e pedagógico que se estende - com algumas variações importantes, como sugerido anteriormente, após os eventos de maio de 1968 - até o tempo presente.

O eixo desse domínio se deu em torno da descoberta do sistema nervoso, substituto parcial da carne cristã, possibilitando uma anatomia política do corpo, supostamente científica, à luz da qual se poderia dominar o prazer nele circulante, ordenar sua energia por meio de certa organização fisiológica e aparelhar seus instintos em face de um desejo capaz de torna-lo útil, dirigindo suas forças para o trabalho produtivo e para certa sujeição aos 
Rev. Interd. em Cult. e Soc. (RICS), São Luís, v. 7, n. 2, p. 157- 178, jul./dez. 2021

ISSN eletrônico: $2447-6498$

aparelhos estatais. Aí aparece o papel da psiquiatria, das ciências médicas e suas tecnologias que alimentaram todo um conjunto de medidas domesticadoras em relação à circulação do prazer e, consequentemente, aos agenciamentos dos fluxos instintuais pelas instituições. Por seu turno, esses agenciamentos das instituições conferem aos anormais um lugar de exceção, assim como aos deficientes, uma vez codificado seu funcionamento orgânico, sua mecânica instintual e justificado sua ingovernável coordenação entre a sua sexualidade e seus aparatos de contenção subjetiva, um lugar de convivência social regulada em torno dos quais se constituem como um dispositivo de inclusão.

\section{O retardo de Jouy - um caso foucaultiano: entre o estigma e a potência}

As configurações dessa inclusão e daquelas práticas que excluem a anormalidade, como duas faces de uma mesma moeda que se complementam em um mesmo dispositivo de subjetivação, se evidenciam, no curso de Michel Foucault (2010) em análise, ao se reportar a um caso paradigmático: o caso de Charles Jouy. Tal caso ocorreu quando esse jovem adulto, no século XIX, foi acusado de ter cometido abuso sexual contra uma menina, provocando enorme reações na aldeia onde ambos viviam, na França. A garota teria contado aos pais o abuso que, por usa vez, o teriam denunciado à polícia. O próprio governante da aldeia teria se incumbido de assumir o caso e levá-lo a justiça que, por sua vez, recorreu aos psiquiatras para constatar a idiotia de Jouy e de sua debilidade que, em face deste diagnóstico médio, o julgou incapaz de reconhecer a gravidade de seu ato sexual, sendo encaminhado ao sanatório. Em tal caso, segundo Foucault:

o ato e os estigmas se referem - um e outros, e de certo modo no mesmo plano,
mesmo se sua natureza é diferente - a um estado permanente, a um estado
constitutivo, a um estado congênito. as dismorfias do corpo são, de certo modo, as
consequências físicas e estruturais desse estado, e as aberrações de conduta,
precisamente as que valeram a jouy sua inculpação, são suas consequências
instintivas e dinâmicas. ( 2010, p. 261$)$

Não se trata nesse caso em demarcar o excesso como uma energia que transgrida ao mecanismo instintual e ao funcionamento biológico, mas de diagnosticar a sua insuficiência, a sua falta e a interrupção de um funcionamento anátomo-fisiológico do corpo que o impede de tornar-se útil e produtivo. São os seus déficits que passam a interessar, ao que tudo indica aparecendo aí um estado de anomalia que, mais tarde, será conhecido como deficiência. Considerando esses aspectos da falta diagnosticada e do déficit, em segundo lugar, a 
Rev. Interd. em Cult. e Soc. (RICS), São Luís, v. 7, n. 2, p. 157- 178, jul./dez. 2021

ISSN eletrônico: 2447-6498

psiquiatria ultrapassou o registro de inscrição da patologia, deslocando para a mecânica do instinto o signo da anomalia. Isso porque, segundo Foucault (2010, p. 262):

\begin{abstract}
Não há doença intrínseca ao instinto, há uma espécie de desiquilíbrio funcional do conjunto, uma espécie de dispositivo ruim nas estruturas, que faz que o instinto, ou certo número de instintos, se ponha a funcionar "normalmente", de acordo com seu regime próprio, mas "anormalmente" no sentido de que esse regime próprio não é controlado por instâncias que deveriam precisamente assumi-los, situá-los e delimitar sua ação.
\end{abstract}

Isso significa dizer que, no caso de Charles Jouy, o não acompanhamento de suas faculdades superiores com seu desenvolvimento biológico e seu corpo sexual, produziram esses déficits, ao ponto de poderem ser averiguados pelas dimensões de seus próprios órgãos, marcas fenotípicas e dimensões físicas de seus ossos. Foram esses aspectos que se inscrevem num corpo orgânico individual e se expressam em sua superfície que serviram para justificar seu retardo e a manifestação de ímpetos animais tão descontrolados, ingovernáveis por ele próprio.

A sua imbecilidade é definida assim como fruto dessa condição, de acordo com o diagnosticado, assim como a de todos aqueles cuja superfície de inscrição física passa a ter dimensões estranhas de ossos, órgãos e músculos, disfunções instintuais agressivas ou de comportamentos não condizentes ao engenho mental esperado por parte do indivíduo em geral e universalmente almejado pela psiquiatria. Daí em diante é esse desenvolvimento geral da subjetividade e a sincronia dos três aspectos relacionados aos fatores biológicos, instintuais e sexuais que a constituem começam a servir de parâmetro para o diagnóstico e para o registro científico da divisão entre o normal e o anormal, se apresentando como um paradigma moderno para diversas artes ou tecnologias de governo como as médicas, as psicológicas, as pedagógicas e as jurídicas.

Essa situação institucional foi percebida, porém, pela transversalidade de deformações manifestas e disfuncionalidades que repercutem no corpo, de um fluxo e circulação de instintos e de uma economia do prazer cujo objeto daqui para diante serão objetos da psiquiatria, identificando aí traços de infantilidade e de debilidade no adulto, que podem ser antecipados com acuidade no corpo infantil. No âmbito psiquiátrico, esses indicadores corpóreos:

[...] serão submetidas de pleno direito à inspeção psiquiátrica todas as condutas da criança, pelo menos na medida em que são capazes de fixar, de bloquear, de deter a conduta do adulto, e se reproduzir nela. E, inversamente, serão psiquiatrizáveis todas as condutas do adulto, na medida em que podem, de uma maneira ou de outra, na forma da semelhança, da analogia ou da relação causal, ser rebatidas sobre e 
Rev. Interd. em Cult. e Soc. (RICS), São Luís, v. 7, n. 2, p. 157- 178, jul./dez. 2021

ISSN eletrônico: 2447-6498

transportadas para as condutas da criança. Percurso, por conseguinte, integral de todas as condutas da criança, pois elas podem trazer consigo uma fixação adulta; e, inversamente, percurso total das condutas do adulto para desvendar o que pode haver nelas em matéria de traços de infantilidade. É esse o primeiro efeito da generalização que é levada por essa problematização da infância, ao próprio âmago do campo da psiquiatria. Em segundo lugar, a partir dessa problematização da infância e da infantilidade, vai ser possível integrar uns aos outros três elementos que haviam ficado, até então, separados. Esses três elementos são: o prazer e sua economia; o instinto e sua mecânica; a imbecilidade ou, em todo caso, o retardo, com sua inércia e suas carências. (FOUCAULT, 2010, p. 267)

Ao considerar esses três elementos a psiquiatria do século XIX, estende dessa forma a patologização do instinto por meio de sua mecânica, separando-a da economia do prazer, centrando a imbecilidade ora como uma extrapolação desta última na forma de delírio, ora como uma inércia instintual, gerando a demência. Mais do que o seu desenvolvimento anatômico-biológico não corresponder ao de suas faculdades intelectuais, essa forma de patologização do instinto que serve para julgá-lo, seja para vislumbrar aspectos de eventuais correções, seja para reconhecer a sua inércia, reiterar seu retardo, neutralizando certas potências nocivas identificadas com o prazer sexual e sua economia.

Esse julgamento negativo em relação ao corpo sexual do anormal, onde os prazeres circulam e podem curto-circuitar as relações de poder no tecido social, gerando anomias e interpelando os limites da própria normalidade, sendo vistos ora como ameaça a ser evitada, corrigida e anulada, ora como uma força ingovernável, a ser deixada à própria sorte, enclausurada, excluída da esfera pública. É esse efeito que o registro da deficiência a um estado geral do corpo orgânico, instintual e sexual, como uma condição pessoal que encarna o registro na anormalidade suscita, conjuntamente à sua consequente identificação com um estigma, que entra em circulação pelos discursos e pelas suas formações sociais.

Num caso como o de Charles Jouy, porém, as personagens do pequeno masturbador, do grande monstro e do indisciplinado se fundem, ao demonstrar que a sua dinâmica instintual é disfuncional, seus prazeres estão descolados dessa mecânica e ocorrem num nível infantil, ao menos assim diagnosticado pelos saberes psiquiátricos, como se esse traço de infantilidade determinasse o seu retardo. Por sua vez, se nessa defasagem entre o instinto e o prazer, a debilidade emerge como uma força, inscrevendo sobre seu corpo o registro do retardo, o caso pode ser generalizável como faz a psiquiatria, encontrando uma lei geral no registro da ciência e na transformação da exceção em anormalidade a ser combatida. Esse procedimento é até hoje utilizado pelos saberes e técnicas médicas, psicológicas, pedagógicas, ao tratar de uma generalização honestamente impossível, uma vez que o caso está entre a 
Rev. Interd. em Cult. e Soc. (RICS), São Luís, v. 7, n. 2, p. 157- 178, jul./dez. 2021

ISSN eletrônico: $2447-6498$

exceção e a regra, a diferença de uma singularidade e o comum desenhado por essas diferenças.

É nessa generalização em que esse saber opera como científico, médico e institucionalizado, mas o problema é que, como mencionado, nem todo verdadeiro nem todo legítimo, ele converte esse registro em um estado de desequilíbrio, isto é, numa condição de que, sem ser patológico, deixa de ser normal. Assim a disfunção, o desiquilíbrio, certas defasagens, são determinadas como um estado de anomalia ou de anormalidade sem que esteja implicado com alguma morbidez, mas que repercuta como uma condição congênita ou adquirida do indivíduo. É o mesmo que dizer que a sua institucionalização traz consigo o registro de um julgamento sobre a ontologia daquelas diferenças, apoiada no diagnóstico dessas defasagens, juntamente com o seu estigma, que condena socialmente o ser ao qual se atribui ou o corpo que a encarna a um déficit ontológico determinado racionalmente e sobre o qual se opera institucionalmente segregações legítimas, inclusões-excludente mediante compensações tecnológicas e adaptativas que nem sempre consideram a sua potencialidade e, nessa perspectiva ôntica, os devires clandestinos que os habitam.

O que significaria levar em conta, todavia, essa (bio)potencialidade desses seres, a ingovernabilidade desses corpos que trazem inscritos esses déficits e, de certo modo, uma (de?) ontologia dessa deficiência que forçam nas relações com outros, na medida em que outrem não esteja fechado a isso, um olhar para devires minoritários que também são seus? Para responder parcialmente essa pergunta, teríamos que ultrapassar o projeto foucaultiano, uma vez que não daria conta de responder a essa questão específica, caminhando na sequência comalgumas reflexões que vimos fazendo com Catherine Malabou (2014) e os mil platôs de Gilles Deleuze e Felix Guattari (2012) sobre a radicalidade ontológica da deficiência.

\section{Da radicalidade ontológica do acidente da deficiência e os devires minoritários}

Para pensarmos a deficiência não como um estado de anormalidade ou como um registro social que predetermina o julgamento negativo dessa designação, mas como os efeitos de uma força desreguladora que se inscrevem no corpo. Tais efeitos podem se singularizar em função não somente de parâmetros biológicos de normalidade, da regulação de uma mecânica instintual e da predeterminação de uma economia do prazer, mas do acidente que o atravessa, da inoperância de seu maquinismo e da recriação de outra forma de subjetivação em que a dinâmica libidinal ocorre por meio da interposição de sua face 
Rev. Interd. em Cult. e Soc. (RICS), São Luís, v. 7, n. 2, p. 157- 178, jul./dez. 2021

ISSN eletrônico: 2447-6498

energética à mecânica instituída. Ao ser pensada dessa forma, segundo um paradigma estético e uma economia do prazer, a deficiência é um modo de existência em que seu processo de subjetivação se compõe por múltiplos devires como quaisquer outros. Contudo, esses devires são agenciados majoritariamente em torno desse seu signo - que lhe é atribuído e que o designa socialmente -, mas que, em sua singularidade, se compõe com outros devires minoritários (e majoritários) que o atravessam, configurando uma linha clandestina dos corpos que os encarnam e dos seres que os potencializam como forma de vida que se afirma na, com a e pela diferença.

É essa diferença particular que, como outra qualquer, perturba pela diferenciação suscitada e pela revolta dos devires alheios que provoca em seus eventuais encontros. Esses últimos podem ou não se tornarem um acontecimento tanto para outrem quanto para essa forma de subjetivação que produz, dependendo do contexto, da abertura do tecido social e da percepção para seu acolhimento por esse outro e do trabalho ético de si, de sua expressão e de potencialidade de afecção. No caso específico dessa diferenciação, o que se pode dizer é que, antes do que ser um estado de anomalia que se atribui a qualquer um a partir de um diagnóstico médico-psiquiátrico ou um estigma que se cola ao seu corpo por ultrapassar o desvio padrão, a sua relação com o acidente praticamente a demarca de maneira decisiva.

Referimo-nos aqui aos efeitos que o acidente produz sobre esse corpo com o qual se faz coincidir essa designação de deficiente, em razão de suas deformações fenotípicas, de suas disfunções orgânicas, de seus desvios instintuais que os tornam diferenciados se comparados à media dos demais indivíduos, sem contar a sua enigmática economia do prazer que escapa àquela controladamente instituída. Nesse corpo singular se inscreve esses efeitos provocados por essa força alheia à vontade individual ou ao que denominamos modernamente de sujeito por ser provocada por acontecimentos históricos traumatizantes ou, mesmo, por acidentes em seu sentido ontológico.

Para Catherine Malabou (2014, p. 29-30), esses “[...] acontecimentos são puras forças que golpeiam, dilaceram e furam a continuidade subjetiva, não autorizando nenhuma justificação ou retomada da psique". Decorrentes de acidades, eles produziriam uma plasticidade destrutiva, como um princípio de não adaptação orgânica. Tal plasticidade implicaria na "possibilidade de mudar de identidade por destruição, a possibilidade da metamorfose aniquiladora”, pois “[...] não aparece como uma virtualidade constante do ser, inscrita nele a título de eventualidade, compreendida em seu sentido biológico e ontológico" (MALABOU, 2014, p. 30). Ao contrário disso, a destruição produzida por essa plasticidade “permanece um acidente", como uma "propriedade da espécie” que inscreve a destruição 
Rev. Interd. em Cult. e Soc. (RICS), São Luís, v. 7, n. 2, p. 157- 178, jul./dez. 2021

ISSN eletrônico: 2447-6498

como possível, em uma estrutura existencial, não reduzindo a um acaso para a sua ocorrência, tampouco a algo que possa ser previsto por algum estatuto. A ontologia do acidente é como "uma lei lógica e biológica", mas que "não se permite antecipar nada sobre seus próprios casos", somente sendo surpreendida por eles e pelo acontecimento da destruição como seu efeito possível - não necessário - sobre uma existência (MALABOU, 2014, p.30). É dessa forma que a plasticidade destrutiva provoca existencialmente certa explosão da identidade e um esfacelamento da subjetividade. Afinal, essa força de destruição repercute sobre o corpo e dilacera a existência, ao ponto de fragmentá-la e de o indivíduo não mais se reconhecer nela ou somente reconhecê-la parcialmente, como assinalado por Pagni (2019).

Malabou (2014, p. 14) argumenta que “[...] o fenômeno da plasticidade patológica, de uma plasticidade que não conserta", nem adapta o organismo a sua nova forma, "corta o fio da vida em dois, ou em vários segmentos que não reencontrarão mais”, exigindo uma fenomenologia própria a ser decodificada e escrita. É essa fenomenologia que a filósofa francesa procura retratar ao considerar algumas transformações ocorridas na identidade subjetiva em casos de pacientes com Alzheimer, dando visibilidade as suas linhas de deriva, ainda que sem se reportar diretamente às curvas enunciativas e aos processos de subjetivação propriamente ditos - como talvez fosse mais adequado a uma cartografia. De qualquer forma, essas linhas seriam geridas, antes do que pela astúcia, estratagemas ou máscaras tipológicas, por uma ontologia e uma clandestinidade existencial que tornaria irreconhecível tais sujeitos para si mesmos, uma vez que sua escultura interior, moldada não em sua aparência externa, mas pelos sinais da força da plasticidade destrutiva para a qual não há saída, salvo aceitar a transformação que provoca sobre o corpo. Dessa forma, a plasticidade destrutiva "torna possível a aparição ou a formação da alteridade lá onde o outro falta absolutamente" (MALABOU, 2014, p. 17), uma vez que para tais pacientes só é possível buscar uma forma de fuga, contornando a identidade que os desertaram, deixando-os à deriva como indivíduos.

Essa deriva não decorre de uma interdição dos instintos ou no bloqueio de seus fluxos ou tendências por meio de dispositivos que os organizam e os dirigem no ambiente institucional, para usar expressões de Foucault (1990). Tampouco é produzida por alguma máquina abstrata de rostidade, nos termos literais de Deleuze e Guattari (2004). Trata-se de uma força destrutiva com a qual esses corpos arcam, constituindo os seus órgãos ou sua reorganização, até com certa sabedoria corpórea por assim dizer, que se, por um lado, limita o seu emparelhamento a uma mecânica instintual ou a uma economia libidinal prévia, por outro, cria artesanalmente um maquinismo inconsciente singular, distinto do conhecido como normal e provocativo de sua regulação maquínica coletiva praticada pela instituição. 
Rev. Interd. em Cult. e Soc. (RICS), São Luís, v. 7, n. 2, p. 157- 178, jul./dez. 2021

ISSN eletrônico: $2447-6498$

Aquele maquinismo nem sempre visível pela instituição, mas é comum que nela, ao aglutinar as diferenças em torno do vazio com que pratica essa forma de alteridade, a reunião de devires clandestinos em torno de certa interconexão, sem qualquer comunicação (GIL, 2019). É preciso destacar que os efeitos de-formativos, defeitos funcionais e desvios instintuais provocados por essa força sobre o corpo e que nele se inscrevem - e não apenas sob a superfície da pele -, constituem uma forma de alteridade com o acidente, isto é, com esse outro de si que falta, que esfacela qualquer identidade e que faz com que esses corpos se tornem irreconhecíveis para si mesmos.

Essa forma ímpar de alteridade dos pacientes com Alzheimer salientadas por Malabou (2012) parece ser familiar à convivência com os efeitos causados pelos seus acidentes e produtores de déficits em suas formas de vida ou os modos de existência denominados de deficientes. Diferentemente de um estado de registro médico do qual não escapam por sua condição de inscrição, desse ponto de visa é essa convivência com os efeitos dos acidentes sobre o corpo que demarcam esses modos de existência, sendo o encontro com tais efeitos um primeiro indício da possibilidade de seu corpo deformado, disfuncional, em déficit, se tornar para si um acontecimento Assim, escapam a uma condição de registro (médica, antropológica, sociológica) para se constituir num campo de inscrição do acontecimento, da diferença que produz e das forças desreguladoras que exprimem, evidenciando por esse prisma sua potência nem sempre convertida em ato, mas sempre uma pulsação da bíos.

Por essa razão, a convivência com esses efeitos se torna constitutivo desse modo de ser e se apresenta como uma das condições do humano, similarmente a outras como as relacionadas à fragilidade e à finitude do homem, porém, despertando-as para sua inumanidade e para os devires outros comuns. Nisso consiste a sua radicalidade ontológica, pois, na medida em que esses seus efeitos produzem alterações demandadas tanto pela instituição quanto pelo instinto, ela consiste numa experiência com uma força destrutiva produzida por uma relação ontológica cuja localização, previsão e racionalidade ou regularidade são imprevisíveis para existência. Essa radicalidade ontológica que o acidente produz nos modos de existência em geral, assume a nosso ver uma configuração ímpar em relação às formas de vida cujo signo da deficiência se sobreleva, dando corpo a um devir minoritário - o dos déficits - em detrimento de outros (relacionados aos gênero, à sexualidade, às condições de vulnerabilidade ou étnico-raciais, dentre outras, igualmente minoritários). Se, por um lado, tal radicalidade produz um déficit ontológico, nos termos anteriormente mencionados, por outro, ela demarca uma singular subjetivação. Por mais que se tente capturar essa forma de subjetivação institucionalmente, mobilizando para tanto os 
Rev. Interd. em Cult. e Soc. (RICS), São Luís, v. 7, n. 2, p. 157- 178, jul./dez. 2021

ISSN eletrônico: 2447-6498

saberes médico-psiquiátricos, suas tecnologias ou, mesmo, dispositivos mais complexos para correspondê-la a um "ser menos", esses corpos fogem a essa captura, quase como uma condição existencial de suas tendências instintuais, sem síntese prévia, talvez, somente a posteriori e, em geral, em afronta ao instituído.

Este a nosso ver é o impasse do corpo em que sobreleva o signo da deficiência sobre outros devires que na sua significância não se deixam capturar e que se mantêm literalmente vivo. Como diz Malabou (2014, p. 22): “[...] a síntese de uma alma e de um corpo outros em sua própria deserção é ainda uma forma, um todo, um sistema, algo vivo". Essa remissão ao vivo e as forças evocam, seguramente, a ingovernabilidade desses modos de existência, da circulação de seus instintos e de uma economia do prazer, que ultrapassa o saber biológico e as tecnologias do eu, despertando os devires animais, fêmeas, negros, juntamente com os deficientes, de modo a suscitar em outrem um deslocamento. Quem sabe até invoquem, com isso, uma rebelião desses devires em torno do corpo deficiente uma familiaridade e um jogo que afronta a monotonia majoritária dos devires brancos, másculos, heterossexuais, europeus, que nos dão um rosto.

Sob esse aspecto não poder-se-ia mais se referir a esses devires provocados em torno de um vazio com o qual praticam a alteridade, denotadamente por sua ausência de um código prévio qualquer ou de uma gramática que o subjugue, a uma relação estratificada de indivíduo, já que sequer a identidade para tal se tem naqueles corpos acometidos pela força destrutiva do acidente. Somente os encontros desses corpos que trazem inscritos os efeitos dos acidentes e que exprimem a potência do signo da deficiência, dentre outros que os atravessam e os quais mobilizam nessa relação com outrem, poderiam agenciar esses devires. Se, desse ponto de vista, não se pode reportar a uma relação individualizada, também não se pode falar de uma força coletiva como produção de uma máquina abstrata, é possível falar de uma força dispersa, caótica, que se reúne em torno do comum e dos devires que comungam. Essa comunhão se dá em torno das diferenças ontológicas em torno das quais podem se aglutinar tanto por critérios identitários ou significantes, isto é, dos signos atribuído a um ou outro devir minoritário da espécie ou do povo que falta - deficiente, negro, índio, travesti, em situação de vulnerabilidade social ou fragilidade de qualquer tipo - quanto por critérios de inclusão disjuntiva ou de alianças inconfessáveis - dada aleatoriamente pelas lutas transversais de governamentalidade, pelos jogos de poder e pela criação de subjetivações insurgentes que resistem ou produzem linhas clandestinas às hegemônicas no capitalismo.

Esses devires que, juntamente com uma rostidade clandestina, dão pulso à vida possuem um móvel destrutivo, mas que, ao mesmo tempo, desestabiliza e força outro fluxo 
em outrem, por meio de uma economia do prazer desconhecida, ainda que percebida como vital. E, mesmo nesse potencial destrutivo, se interpõe à destruição interposta pela regulamentação do sistema em seu maquinismo capitalista e, em especial, nas tendências fascistas que se maquinam com o neoliberalismo. Essa percepção desafia a filosofia a trabalhar sem a regularidade de uma lei, ao mesmo tempo biológica e ontológica, ou racionalidade prévia, conclamando-a a atentar a esses acidentes, os efeitos que produzem nesses corpos e aos acontecimentos produzidos por seus encontros com outros corpos, demandando para tanto a parceria com outras artes. Assim, ao mesmo tempo em que esse móvel destrutivo ao qual a vida resiste impacta tanto os fluxos libidinais quanto a sua maquinação empreendida pelas instituições no sentido de coordená-los, dirigi-los e conduzilos, ele também desafia os corpos a se encontrarem com outros produzindo uma biopotência a ampliar a fratura biopolítica, com uma postura de abertura a alianças entre as diferenças significadas que a promovam na criação de um comum por vir. Desafia ainda para tal a mobilização da filosofia em aliança com as artes, para além da adoção de um paradigma científico cego em relação ao campo estético da emergência do acontecimento desses encontros de corpos que fariam os devires minoritários circularem, afrontando os majoritários, assim como agenciarem um inconsciente maquínico para o qual as intensidades do prazer e os fluxos do desejo potencializassem a criação de uma trans-subjetivação-comum.

\section{A potência do retardo de Jouy e a clandestinidade do devir deficiente na escola}

Para essa última possibilidade, quem sabe, a deficiência como um signo que se sobreleva a outras diferenças seria vista não para minorizar o ser por sua face inumana, mas para se colocar em face da encarnação desse signo como uma potência irruptiva e, portanto, como índice da criação de modos de existência outros e de retroalimentação da (bíos) política. Não temos condições de desenvolver aqui o quanto as tecnologias e os dispositivos de inclusão são formulados, conjuntamente a todo um aparato político, para promover essa maquinação institucional dos instintos e minar qualquer insurgência de suas forças ingovernáveis, dentre as quais, aquelas que se produzem na e com a deficiência. Isso porque esses corpos não somente desafiam a normalidade reinante, suas regularidades, como também trazem à luz a sombra do acidente para os demais, assim como a possibilidade de se conviver com essa sombra não de modo somente a iluminá-la, como também a habitá-la em seu limiar de existência e, ao mesmo tempo, no trabalho artístico de sua recriação. Nessa arte o material não seria somente os órgãos do corpo biológico, tampouco a codificação da mecânica 
Rev. Interd. em Cult. e Soc. (RICS), São Luís, v. 7, n. 2, p. 157- 178, jul./dez. 2021

ISSN eletrônico: 2447-6498

instintual, como também, e principalmente, toda uma economia dos fluxos de prazer insubordináveis à cognição - o que implica a impossibilidade do retardo como no caso de Jouy e sim compreender essa configuração como um modo singular de vida -, a uma harmonia orgânica centrada no sistema nervoso ou a um desenho analítico prévio da libido.

Sob essa ótica a inculpabilidade atribuída a Jouy em razão de seu retardo, isto é, ao seu ato ser inculpável uma vez que em seu corpo adulto habitar uma cognição infantil, se a retomássemos à guisa de conclusão, seria justamente essa diferença que nos interessaria como fonte de sua potência e como objeto de uma cartografia, assim como fez Fernand Deligny (2007) em sua obra. Quando esse outro não significa o acontecimento que encarna diante do acidente sofrido, essa cartografia pode ajudar ao menos aqueles que comungam com eles devires minoritários a percebê-los como afecção e a acolhê-los como uma potência pura. Isso porque não são todos que, como retratado por Deleuze (2001) ao analisar a obra do poeta Joe Busquet, encarnam essa ferida. Uma vez que o acidente divide a vida em um antes e um depois, há para alguns corpos feridas que nunca se fecham, estão ali como um sempre acidente, desde o nascimento, não havendo qualquer outro tipo de experimentação da existência sem os efeitos deste último. Ou, ainda, pode se dizer que há caso em que a vida se dá por ela mesma, com uma organização de órgãos bastante singular, com uma mecânica instintual própria e uma erótica ou economia libidinal (in) comum, onde nesse caso ela é somente experimentada pelo acidente, não fazendo dele experimentação, se subjetivando nessa sua forma bruta em que o encontro com ela acontecer só se torna acontecimento para esse outro, jamais para si ou para si de maneira muito, muito particular.

Isso significaria que esse "em si" da deficiência seria ele mesmo insondável e, portanto, passível de aproximação no processo de alteridade somente por um terceiro, por outrem, desde que esse outrem pudesse por associações de familiaridade e de jogos (de linguagem) específicos projetar-se nele para sair de si, inoperosamente, afetivamente. Esse nos parece ser o gesto ético mais importante e mais generalizável dessa relação com a deficiência em sua radicalidade ontológica, ao mesmo tempo o ato político mais subversivo a nos permitir valorar nessas vidas e corpos que a encarnam como um signo significável ou não um potencial de "ser mais", porque mais intensa e potente para a criação da existência e para liberar sua ingovernabilidade, mesmo em contexto como os atuais que a denegam. Dessa forma, talvez, tivéssemos um homem que faz instituição não sem instinto, mas com uma inumanidade que está presente e em cujos devires minoritários se insurgiriam contra a inumanidade do sistema, para usar uma expressão de Lyotard (1997), e, poderíamos acrescer, de majoração subjetiva que segrega para eliminar o minoritário em nós, fazendo morrer o seu 
Rev. Interd. em Cult. e Soc. (RICS), São Luís, v. 7, n. 2, p. 157- 178, jul./dez. 2021

ISSN eletrônico: 2447-6498

móvel: a diferença suscitada pelo acontecimento de seu encontro e a percepção aguda desse devir clandestino de sua própria deficiência.

\section{REFERÊNCIAS}

CHAMAYOU, Gregoire. Sociedade ingovernável. São Paulo, Editora Ubu, 2020.

DELEUZE, Gilles. "Introduction". In: CANGUILHEM, Georges (org.). Instincts et institutions. Paris, Hachette, 1955, pp. VIII-XI.

DELEUZE, Gilles. Lógica do sentido. 4. Ed. São Paulo, Editora Perspectiva, 2000.

DELEUZE, Gilles. Instinto e instituições. In: . A ilha deserta e outros textos: Textos e entrevistas (1953-1974). São Paulo, Editora Iluminuras, 2005.

DELEUZE, Gilles; GUATTARI, Félix. O anti-Édipo: capitalismo e esquizofrenia 1. São Paulo, Editora 34, 2010.

DELEUZE, Gilles; GUATTARI, Félix. Mil Platôs: capitalism e esquizofrenia 2. Vol. e. São Paulo, Editora 34, 2004 [4ª reimpressão].

DELEUZE, Gilles; GUATTARI, Félix. Mil Platôs: capitalism e esquizofrenia 2. 2. Ed. Vol. 4. São Paulo, Editora 34, 2012.

DELIGNY, Fernand. Cahiers de L'Immuable. In: OEUVRES. París, Éditions L'Arachnéen, 2018, pp. 797-1030.

FOUCAULT, Michel. História da Sexualidade I: a vontade de saber. 10. Ed. Rio de Janeiro, Edições Graal, 1988.

FOUCAULT, Michel. Sobre a história da sexualidade. In: ed. Rio de Janeiro, Edições Graal, 1990.

Microfísica do poder. 9.

FOUCAUlT, Michel. O que é crítica?, Cadernos de Filosofia e Ciências, MaríliaFFC/UNESP, v. 9, n. 1, 2000, pp. 169-189.

FOUCAULT, Michel. Os Anormais: curso no Collège de France (1974-1975). 2. Ed. São Paulo, Editora WMFMartins Fontes, 2010.

GIL, José. Caos e ritmo. Lisboa, Relógio D’água editores, 2018.

LYOTARD, Jean François. Dispositivos pulsionales. Madrid, Editorial Fundamentos, 1981.

LYOTARD, Jean François. Economía Libidinal. Buenos Aires, Fondo de Cultura Económica, 1990.

LYOTARD, Jean François. O inumano. 2. Ed. Lisboa, Editorial Estampa, 1997.

MALABOU, Catherine. Ontologia do acidente: ensaio sobre a plasticidade destrutiva. Florianópolis, Cultura e Barbárie, 2014. 
Rev. Interd. em Cult. e Soc. (RICS), São Luís, v. 7, n. 2, p. 157- 178, jul./dez. 2021 ISSN eletrônico: $2447-6498$

PAGNI, Pedro A. Biopolítica, deficiência e educação: outros olhares sobre a inclusão. São Paulo, Editora UNESP, 2019.

PELBART, P. P. Ensaios do assombro. São Paulo, N-1 Edições, 2019. 